\title{
Zircônia ultra translúcida: Revisão de literatura
}

\section{Ultra translucent zircônia: literature review}

\author{
Carolina Caires de Almeida' ${ }^{1}$ (]) \\ Mirna Cristiane Ribeiro Cruz Fernandes ${ }^{2}$ (1) \\ Emilena Maria Castor Xisto Lima3 ${ }^{3}$ (1) \\ Adriana Oliveira Carvalho 4 (i)
}

\begin{abstract}
${ }^{1}$ Autora para correspondência. Faculdade São Leopoldo Mandic (Campinas). São Paulo, Brasil. caires.odontologia@gmail.com ${ }^{2}$ Faculdade São Leopoldo Mandic (Campinas). São Paulo, Brasil. mirnacrcf@yahoo.com.br ${ }^{3}$ Escola Bahiana de Medicina e Saúde Pública (Salvador), Universidade Federal da Bahia (Salvador). Bahia, Brasil. emilenalima@gmail.com ${ }^{4}$ Escola Bahiana de Medicina e Saúde Pública (Salvador), Universidade Estadual de Feira de Santana (Feira de Santana). Salvador, Bahia, Brasil.
\end{abstract} aoc1981@hotmail.com

RESUMO | INTRODUÇÃO: A zircônia ultra translúcida (5Y-PSZ) possui propriedades ópticas superiores comparadas aos sistemas cerâmicos convencionais, proporcionando uma ampla aplicação na Odontologia estética. OBJETIVO: O presente estudo teve como objetivo apresentar informações relevantes sobre a cerâmica 5Y-PSZ. MATERIAL E MÉTODO: Foi realizada uma busca na literatura com artigos que avaliaram especificamente a zircônia ultra translúcida na base de dados PubMed, os artigos selecionados abrangiam o período entre 2010 e 2020, além de utilizar artigos mais antigos a fim de contextualizá-la. RESULTADOS: Os trabalhos selecionados descrevem as propriedades ópticas, mecânicas e aplicações clinicas da 5Y-PSZ. A literatura mostra que a composição química deste material proporciona translucidez maior que as demais zircônias e sua resistência flexural permite seu uso em restaurações unitárias posteriores e anteriores. CONSIDERAÇÕES FINAIS: A adesão não parece um empecilho para indicação desta zircônia em áreas não retentivas, e isso a torna um material promissor para aplicabilidade em laminados cerâmicos adotando-se uma abordagem mais conservadora. No entanto, como a 5Y-PSZ foi desenvolvida recentemente, ainda se faz necessário mais estudos que avaliem suas propriedades e diferentes situações clínicas para que o dentista eleja este material com confiança na prática clínica.

PALAVRAS-CHAVE: Cerâmica. Materiais dentários. Cimentação.
ABSTRACT | INTRODUCION: Ultra translucent zircônia (5Y-PSZ) has superior optical properties compared to conventional ceramic systems, providing a wide application in aesthetic dentistry. OBJECTIVE: The present study aimed to present relevant information about 5Y-PSZ ceramics. MATERIAL AND METHOD: A literature search was performed with articles that specifically evaluated ultra translucent zircônia in the PubMed database, the selected articles covered the period between 2010 and 2020, in addition to using older articles a in order to contextualize it. The selected papers describe the optical, mechanical and clinical applications of 5Y-PSZ. RESULTS: The literature shows that the chemical composition of this material provides greater translucency than other zircônia and its flexural strength allows its use in posterior and anterior unitary restorations. CONCLUSION: Adhesion does not seem to be an obstacle for indicating this zircônia in non-retentive areas, and this makes it a promising material for applicability in ceramic laminates, adopting a more conservative approach. However, as 5Y-PSZ was recently developed, further studies are needed to assess its properties and different clinical situations for the dentist to choose this material with confidence in clinical practice.

KEYWORDS: Ceramics. Substrate. Cementation. 


\section{Introdução}

A zircônia é um material cerâmico empregado na Odontologia que possui excelentes propriedades mecânicas e biocompatibilidade ${ }^{1,2}$. No entanto, a microestrutura cristalina altamente densa da zircônia convencional 3Y-TZP resulta na redução da translucidez, fator limitante para se conseguir uma estética satisfatória que simule o comportamento óptico do esmalte dentário ${ }^{3,4}$. Esta característica tornou-a inapropriada para uso em restaurações na região anterior.

$\mathrm{Na}$ tentativa de agregar boas propriedades ópticas à resistência das zircônias 3Y-TZP, surgiu recentemente no mercado odontológico as zircônias translúcidas, com modificações em sua composição química, a exemplo da maior concentração de óxido de ítrio, que proporciona maior conteúdo de fase cristalina cúbica e, por conseguinte, maior translucidez a estes materiais ${ }^{5,6}$. Dentre estas, a zircônia ultra translúcida 5Y-PSZ, estabilizada com $5 \mathrm{~mol} \%$ de ítria, apresenta características que a tornam uma opção promissora para tratamento reabilitador estético, podendo proporcionar às restaurações um efeito natural? ${ }^{7}$.

No entanto, a melhoria da translucidez da 5Y-PSZ trouxe consequências na resistência flexural desta cerâmica policristalina, que diminuiu consideravelmente quando comparada as zircônias estabilizadas com $3 \mathrm{~mol} \%$ de ítria ${ }^{6,7}$. Ainda assim, a zircônia ultra translúcida apresenta maior opacidade e uma maior resistência flexural que as cerâmicas vítreas ${ }^{5}$. Estas propriedades inerentes à zircônia, permitem a ampliação da sua indicação para restaurações posteriores e coroas monolíticas em regiões anteriores e laminados cerâmicos.

Assim, o objetivo deste artigo foi realizar uma revisão narrativa da literatura sobre a zircônia ultra translúcida, abordando suas propriedades ópticas, composição química, resistência e adesão, visando uma meIhor compreensão acerca da viabilidade na indicação deste material para uso clínico.

\section{Material e metódo}

Este trabalho é uma revisão da literatura narrativa, descritiva, realizado por meio do levantamento bibliográfico de artigos disponíveis no banco de dados Medline (PubMed) que abordavam o tema proposto. Para isso, foram utilizados os seguintes descritores: "zircônia translúcida", "zircônia monolítica" e "zircônia ultra translúcida" utilizados na língua inglesa, correspondendo as plavaras-chave: "translucent zircônia", "monolithic zircônia" e "ultra translucent zircônia", respectivamente.

A busca de dados ocorreu no ano de 2020 e os artigos selecionados respeitaram a linha do tempo de 2010 a 2020. No entanto, alguns artigos mais antigos foram coletados a fim de contextualizar o histórico deste material cerâmico. Foram excluídos os artigos que não se adequavam ao estudo por não abordarem, especificamente, o tema da zircônia ultra translúcida. Foram selecionados 36 artigos na língua inglesa, para elaboração desta revisão, que estudaram a temática proposta.

Os conteúdos explorados nos artigos permitiram que a organização em subtemas fosse desenvolvida nesta revisão: propriedades ópticas e propriedades mecânicas.

\section{Revisão de literatura}

As cerâmicas policristalinas de zircônia tetragonal, estabilizadas por 3 mol\% de ítria (3Y-ZTP), têm sido utilizadas como material restaurador odontológico com sucesso, podendo ser empregadas para infraestruturas de coroas unitárias e próteses fixas8. A vantagem desta zircônia contendo estrutura cristalina tetragonal é sua alta resistência flexural à fratura, superior a $1000 \mathrm{MPa}^{1,9,10}$. Esta excelente propriedade deve-se ao fato do material responder ao estresse mecânico por meio da tenacificação por transformação $(t \rightarrow m)$, processo capaz de impedir que uma fratura se propague. 
Ainda que essa seja considerada a cerâmica mais resistente e tenaz utilizada em Odontologia, a sua estética e, particularmente, sua translucidez, tem sido um dos maiores desafios na utilização desse material 5 . Devido a cor branca opaca e translucidez insuficiente deste material, faz-se necessário um revestimento de porcelana feldspática vítrea para obter uma aparência natural e uma estética aceitável. A alta opacidade da 3Y-ZTP torna-se um problema, principalmente, ao confeccionar uma coroa ou uma prótese parcial fixa anterior na presença de um dente natural adjacente, pois nestes casos, a refletância e a dispersão da luz nem sempre são semelhantes ao dente natura|8,11.

O recobrimento com porcelana feldspática é utilizado para mascarar a infraestrutura opaca de zircônia e aproximar as propriedades ópticas da dentição natural adjacente ${ }^{10}$. Entretanto, esta cerâmica de cobertura está sujeita à falhas, principalmente, pela delaminação do material. As possíveis causas do lascamento do material de cobertura são: diferenças no coeficiente de expansão térmica (CTE) entre infraestrutura e porcelana, retração de queima da porcelana, porosidades, design e estrutura inadequada para apoiar a porcelana de revestimento, além de sobrecarga e fadiga ${ }^{3,12}$.

Várias soluções foram propostas para superar o problema de delaminação da cerâmica devido à sua natureza multifatorial, tais como a utilização de restaurações feitas em zircônia monolítica, ou seja, sem a necessidade de uma camada de porcelana de cobertu$\mathrm{ra}^{12}$, viabilizadas pelas técnicas de confecção do corpo cerâmico através da tecnologia CAD/CAM (Computeraided Design/Computer-aided Manufacturing) ${ }^{7,13}$. Com o advento das restaurações monolíticas, a camada de revestimento ou cobertura passa a ser eliminada, 0 que reduz o tempo de fabricação e aumenta conside- ravelmente a resistência ao lascamento e à fratura do material11. Além do que, este tipo de restauração pode proporcionar desgastes dentários com finalidade protética mais conservadores.

As restaurações de zircônia monolítica têm uma geometria complexa e são expostas a várias etapas de processamento, incluindo o processo de fresagem, sinterização, jateamento e polimento. Essas etapas influenciam as características da superfície do material e podem levar a microtrincas na restauração que reduzem sua resistência .

Em 2015 foi lançado no mercado odontológico a zircônia ultra translúcida, contendo uma proporção de fase cúbica em torno de $50 \%{ }^{14}$. Assim, passou a apresentar uma estrutura mista, pela presença das fases cúbica e tetragonal similares. Os cristais cúbicos têm um volume maior em comparação aos tetragonais e dessa maneira a luz se espalha com menos intensidade nos limites dos grãos e nas porosidades residuais, tornando o material mais translúcido $\underline{15,16}$.

Além disso, as estruturas cristalinas cúbicas são mais isotrópicas do que as estruturas tetragonais, o que significa que a luz incidente é emitida de forma uniforme em todas as direções espaciais ${ }^{7}$. Esta propriedade também tem uma influência significativa na translucidez. As características de translucidez e a resistência flexural entre 600 a $750 \mathrm{MPa}^{14}$, torna viável o uso deste material em restaurações em regiões anteriores e posteriores. Por ser um material novo, ainda há poucos estudos sobre esta zircônia na literatura. Em suma, as pesquisas mais recentes estão voltadas para avaliação da translucidez, composição química, efeito hidrotérmico e quantificação da passagem de luz através deste material, como mostra o quadro 1, que apresenta os principais objetivos, metodologias e resultados destas investigações. 
Quadro 1. Pesquisas que utilizaram a zircônia ultra translúcida (continua)

\begin{tabular}{|c|c|c|c|c|}
\hline Autor & Objetivo & Material & Método & Conclusão \\
\hline $\begin{array}{l}\text { Harada et al } \\
2015^{5}\end{array}$ & $\begin{array}{l}\text { Avaliar a } \\
\text { translucidez das } \\
\text { zircônias } \\
\text { translúcidas } \\
\text { recentemente } \\
\text { desenvolvidas e } \\
\text { compara-las com } \\
\text { o dissilicato de } \\
\text { lítio. }\end{array}$ & $\begin{array}{l}\text { Zircônias: Prettau } \\
\text { Anterior } \\
\text { (Zirkonzahn), BruxZir } \\
\text { (Glidewell), Katana } \\
\text { HT, Katana ST, and } \\
\text { Katana UT (Kurary } \\
\text { Noritake); e } \\
\text { dissilicato de lítio: } \\
\text { e.Max CAD LT } \\
\text { (Ivoclar Vivadent) }\end{array}$ & $\begin{array}{l}\text { Um espectrofotômetro } \\
\text { (Evolution } 300 \text { UV-Vis) } \\
\text { com uma esfera } \\
\text { integradora foi usado } \\
\text { para avaliar a } \\
\text { transmitância total da } \\
\text { luz como uma } \\
\text { porcentagem (Tt\%) no } \\
\text { comprimento de onda } \\
\text { de } 555 \text { nm para } \\
\text { comparação entre os } \\
\text { grupos. }\end{array}$ & $\begin{array}{l}\text { Com uma espessura } \\
\text { de } 0,5 \mathrm{~mm} \text {, o Katana } \\
\text { UT foi } \\
\text { significativamente } \\
\text { mais translúcido do } \\
\text { que todas as outras } \\
\text { zircônias, e o e-Max } \\
\text { CAD LT foi } \\
\text { significativamente } \\
\text { mais translúcido do } \\
\text { que todas as } \\
\text { zircônias. }\end{array}$ \\
\hline $\begin{array}{l}\text { Putra et al } \\
2016^{15}\end{array}$ & $\begin{array}{l}\text { Avaliar o efeito do } \\
\text { tratamento } \\
\text { hidrotérmico na } \\
\text { transmissão da luz } \\
\text { de zircônias } \\
\text { translúcidas para } \\
\text { restaurações } \\
\text { monolíticas. }\end{array}$ & $\begin{array}{l}\text { Zircônias: BruxZir } \\
\text { Anterior Solid } \\
\text { Zircônia (BruxAnt, } \\
\text { BA), Lava Plus/ alta } \\
\text { translucidez/ (LPHT), } \\
\text { Katana Zircônia } \\
\text { Super Translucida } \\
\text { (KST), e Katana } \\
\text { Zircônia Ultra } \\
\text { Translucida (KUT); e } \\
\text { dissilicato de lítio: } \\
\text { e.Max Press LT } \\
\text { (LDLT) }\end{array}$ & $\begin{array}{l}\text { Um espectrofotômetro } \\
\text { (Evolution } 300 \text { UV-Vis; } \\
\text { Thermo- Fisher) com } \\
\text { uma esfera integradora } \\
\text { foi usado para avaliar a } \\
\text { transmitância total da } \\
\text { luz como uma } \\
\text { porcentagem (Tt\%) } \\
\text { Análises de difração de } \\
\text { raios-X para medir a } \\
\text { transformação de fase } \\
\text { tetragonal-monoclínica. } \\
\text { As superfícies foram } \\
\text { examinadas por } \\
\text { microscopia eletrônica } \\
\text { de varredura e } \\
\text { espectrometria de } \\
\text { energia dispersiva. }\end{array}$ & $\begin{array}{l}\text { O tratamento } \\
\text { hidrotérmico teve } \\
\text { efeitos mínimos na } \\
\text { translucidez das } \\
\text { zircônias } \\
\text { translúcidas. A taxa } \\
\text { de transformação de } \\
\text { fase tetragonal- } \\
\text { monoclínica de } \\
\text { zircônias translúcidas } \\
\text { foi baixa, exceto no } \\
\text { grupo LPHT. }\end{array}$ \\
\hline $\begin{array}{l}\text { Kwon et al } \\
2017^{14}\end{array}$ & $\begin{array}{l}\text { Comparar a } \\
\text { resistência à } \\
\text { flexão, a } \\
\text { translucidez, a } \\
\text { resistência de } \\
\text { união e o desgaste } \\
\text { do esmalte entre } \\
\text { as zircônias } \\
\text { translucidas e o } \\
\text { dissilicato de lítio } \\
\text { (e.Max CAD). }\end{array}$ & $\begin{array}{l}\text { Zircônias: 5Y-ZP } \\
\text { (Katana UTML) e 3Y- } \\
\text { TZP (Katana HT); e } \\
\text { dissilicato de lítio } \\
\text { (e.Max CAD LT). }\end{array}$ & $\begin{array}{l}\text { A translucidez foi } \\
\text { mensurada por um } \\
\text { espectrofotômetro } \\
\text { (CM-700d; Konica } \\
\text { Minolta); a resistência } \\
\text { de união através de } \\
\text { uma máquina de teste } \\
\text { universal (5565; } \\
\text { Instron). O teste de } \\
\text { desgaste foi realizado } \\
\text { com uma carga de } 20 \mathrm{~N} \\
\text { por } 300.000 \text { ciclos em } \\
33 \% \text { de glicerina. O } \\
\text { desgaste volumétrico } \\
\text { de zircônia polida, } \\
\text { dissilicato de lítio e } \\
\text { esmalte foi medido } \\
\text { com um perfilômetro } \\
\text { sem contato (Proscan } \\
5000 ; \text { Scantron Ltd) }\end{array}$ & $\begin{array}{l}\text { O 5Y-TZP possui } \\
\text { resistência à flexão e } \\
\text { translucidez } \\
\text { intermediário aos do } \\
\text { 3Y-TZP e dissilicato } \\
\text { de lítio. A resistência } \\
\text { de união a curto e } \\
\text { longo prazo da 5Y-ZP } \\
\text { e 3Y-TZP mostrou-se } \\
\text { semelhante a do } \\
\text { dissilicato de lítio. O } \\
\text { 5Y-ZP não } \\
\text { demonstrou } \\
\text { desgaste mensurável } \\
\text { do material e } \\
\text { desgaste ao esmalte } \\
\text { oposto, semelhante } \\
\text { ao de todos os } \\
\text { outros materiais } \\
\text { testados. }\end{array}$ \\
\hline $\begin{array}{l}\text { Inokoshi et al } \\
2017^{17}\end{array}$ & $\begin{array}{l}\text { Avaliar a } \\
\text { influência do } \\
\text { jateamento de } \\
\text { alumina em } \\
\text { quatro classes de } \\
\text { zircônia altamente } \\
\text { translúcidas. }\end{array}$ & $\begin{array}{l}\text { Zircônias: KATANA } \\
\text { HT, KATANA STML, } \\
\text { KATANA UTML } \\
\text { (Kuraray Noritake), e } \\
\text { Zpex Smile (Tosoh) }\end{array}$ & $\begin{array}{l}\text { A zircônia recebeu } \\
\text { jateamento com } 50 \mu \mathrm{m} \\
\text { de alumina }\left(\mathrm{Al}_{2} \mathrm{O}_{3}\right) \\
\text { (Kulzer) no grupo teste. } \\
\text { O grupo controle não } \\
\text { recebeu jateamento. A } \\
\text { translucidez foi } \\
\text { mensurada por um } \\
\text { calorímetro. A } \\
\text { rugosidade da } \\
\text { superfície foi avaliada } \\
\text { através de microscopia }\end{array}$ & $\begin{array}{l}\text { O jateamento com } \\
\mathrm{Al}_{2} \mathrm{O}_{3} \text { não aumentou } \\
\text { significativamente a } \\
\text { rugosidade da } \\
\text { superfície das } \\
\text { diferentes zircônia } \\
\text { estudadas, exceto o } \\
\text { KATANA UTML. No } \\
\text { entanto, alterou a } \\
\text { composição da fase e } \\
\text { a presença de tensão } \\
\text { residual na superfície }\end{array}$ \\
\hline
\end{tabular}


Quadro 1. Pesquisas que utilizaram a zircônia ultra translúcida (continuação)

\begin{tabular}{|c|c|c|c|c|}
\hline Autor & Objetivo & Material & Método & Conclusão \\
\hline & & & $\begin{array}{l}\text { confocal a laser 3D. } \\
\text { difração de raios X } \\
\text { (DRX) com análise de } \\
\text { Rietveld foi utilizada } \\
\text { para avaliar a } \\
\text { composição da fase de } \\
\text { zircônia. A } \\
\text { espectroscopia Micro- } \\
\text { Raman foi usada para } \\
\text { avaliar o estresse } \\
\text { residual } \\
\text { potencialmente } \\
\text { induzido. }\end{array}$ & $\begin{array}{l}\text { de todas as zircônias } \\
\text { altamente } \\
\text { translúcidas } \\
\text { investigadas. }\end{array}$ \\
\hline $\begin{array}{l}\text { Zhao et al } \\
2017^{18}\end{array}$ & $\begin{array}{l}\text { Comparar a } \\
\text { translucidez e a } \\
\text { resistência de } \\
\text { cerâmicas } \\
\text { dentárias, } \\
\text { incluindo as } \\
\text { zircônias } \\
\text { translúcidas, o } \\
\text { dissilicato de lítio } \\
\text { e outras } \\
\text { porcelanas de alta } \\
\text { translucidez. }\end{array}$ & $\begin{array}{l}\text { Zpex and Zpex Smile } \\
\text { (Tosoh) BruxZir } \\
\text { (Glidewell). } \\
\text { Dissilicato de lítio HT } \\
\text { (IPS e.Max CAD HT } \\
\text { by Ivoclar Vivadent); } \\
\text { e outras porcelanas } \\
\text { de alta translucidez: } \\
\text { VMK Master (VITA), } \\
\text { Vision- white and } \\
\text { Vision-blue (Vision } \\
\text { USA). }\end{array}$ & $\begin{array}{l}\text { A montagem de fases } \\
\text { das aluminas foi } \\
\text { caracterizada por } \\
\text { análise de difração de } \\
\text { raios-X. A } \\
\text { microestrutura das } \\
\text { aluminas foi observada } \\
\text { por microscopia } \\
\text { eletrônica de varredura } \\
\text { USM-6360LV; JEOL). A } \\
\text { translucidez foi } \\
\text { avaliada por um } \\
\text { espectrômetro (Carry } \\
\text { 5000; Agilent). A } \\
\text { densidade foi medida } \\
\text { pelo princípio de } \\
\text { Arquimedes. }\end{array}$ & $\begin{array}{l}\text { A zircônia 5Y-PSZ } \\
\text { exibem um nível de } \\
\text { translucidez } \\
\text { semelhante a } \\
\text { porcelanas } \\
\text { altamente } \\
\text { translúcidas e maior } \\
\text { que o dissilicato } \\
\text { contendo zircônia. As } \\
\text { recém-desenvolvidas, } \\
\text { zircônias com } \\
\text { submicrons de } \\
\text { alumina, devem ter } \\
\text { melhor resistência à } \\
\text { degradação do que a } \\
\text { cerâmica de vidro, } \\
\text { podendo ser um } \\
\text { material adequado } \\
\text { para restaurações } \\
\text { dentárias. }\end{array}$ \\
\hline $\begin{array}{l}\text { Yan et al } \\
2018^{19}\end{array}$ & $\begin{array}{l}\text { Avaliar a } \\
\text { capacidade de } \\
\text { carga de } \\
\text { dissilicato de lítio } \\
\text { e novos sistemas } \\
\text { restauradores de } \\
\text { zircônia ultra } \\
\text { translúcida de } \\
\text { várias } \\
\text { composições: 5Y- } \\
\text { PSZ (5\% em mol } \\
\text { de zircônia } \\
\text { parcialmente } \\
\text { estabilizada com } \\
\text { ítria) e 4Y-PSZ ( 4\% } \\
\text { molar de zircônia } \\
\text { parcialmente } \\
\text { estabilizada com } \\
\text { ítria); em relação a } \\
\text { 3Y-TZP (3\% em } \\
\text { mol de zircônia } \\
\text { estabilizada com } \\
\text { ítria). }\end{array}$ & $\begin{array}{l}\text { Dissilicato de lítio IPS } \\
\text { e.max CAD (Ivoclar } \\
\text { Vivadent). Zircônias: } \\
\text { Zpex (3Y-TZP) sẹ:Zpex } \\
4 \text { (4Y-PSZ) Zpex } \\
\text { Smile (5Y-PSZ) } \\
\text { (Heany Industries). }\end{array}$ & $\begin{array}{l}\text { Foi avaliado a } \\
\text { resistência a fratura } \\
\text { dos materiais e a } \\
\text { capacidade de carga } \\
\text { pela teoria "Plate-on- } \\
\text { foundation". A } \\
\text { translucidez foi } \\
\text { avaliada por um } \\
\text { colorímetro } \\
\text { (SpectroShade Micro; } \\
\text { MHT) }\end{array}$ & $\begin{array}{l}\text { O 5Y-PSZ é mais } \\
\text { translúcido (apenas } \\
\text { um pouco abaixo do } \\
\text { dissilicato de lítio), } \\
\text { enquanto o } 3 Y \text {-TZP } \\
\text { possui a melhor } \\
\text { capacidade de } \\
\text { suporte de carga. 4Y- } \\
\text { PSZ ocupa o meio } \\
\text { termo. }\end{array}$ \\
\hline
\end{tabular}


Quadro 1. Pesquisas que utilizaram a zircônia ultra translúcida (continuação)

\begin{tabular}{|c|c|c|c|c|}
\hline Autor & Objetivo & Material & Método & Conclusão \\
\hline \multirow[t]{2}{*}{$\begin{array}{l}\text { Mao et al } \\
2018^{20}\end{array}$} & $\begin{array}{l}\text { Avaliar os efeitos } \\
\text { da infiltração com } \\
\text { vidro, abrasão e } \\
\text { polimento sobre a } \\
\text { resistência à } \\
\text { flexão dos } \\
\text { materiais ultra }\end{array}$ & $\begin{array}{l}\text { Zircônia Zpex Smile } \\
\text { (Heany Industries) }\end{array}$ & $\begin{array}{l}\text { A análise } \\
\text { microestrutural foi } \\
\text { realizada por difração } \\
\text { de Raio-X (XRD; } \\
\text { PANalytical X'Pert). A } \\
\text { translucidez através de } \\
\text { um colorímetro }\end{array}$ & $\begin{array}{l}\text { A infiltração de vidro } \\
\text { na superfície da } \\
\text { zircônia diminui o } \\
\text { módulo de } \\
\text { elasticidade da } \\
\text { superfície. Essa } \\
\text { estrutura }\end{array}$ \\
\hline & $\begin{array}{l}\text { translúcidos 5Y- } \\
\text { PSZ recém- } \\
\text { desenvolvidos. }\end{array}$ & & $\begin{array}{l}\text { (SpectroShade Micro; } \\
\text { MHT). O princípio de } \\
\text { Arquimedes foi usado } \\
\text { para as propriedades } \\
\text { físico e mecânicas. }\end{array}$ & $\begin{array}{l}\text { elasticamente } \\
\text { graduada não } \\
\text { apenas melhora a } \\
\text { resistência à flexão e } \\
\text { facilita uma ligação } \\
\text { durável do cimento } \\
\text { resinoso, mas } \\
\text { também fornece } \\
\text { opções de cor e } \\
\text { retém a translucidez } \\
\text { do } 5 Y-P S Z \text {. Por outro } \\
\text { lado, a abrasão a ar e } \\
\text { ao vidro reduzem } \\
\text { significativamente a } \\
\text { resistência da } 5 Y-P S Z \text {, } \\
\text { devido ao reduzido } \\
\text { teor de } \\
\text { transformação } t \rightarrow \text { m } \\
\text { nas zircônias } \\
\text { contendo fase cúbica }\end{array}$ \\
\hline $\begin{array}{l}\text { Yu \& Park } \\
2019^{21}\end{array}$ & $\begin{array}{l}\text { Avaliar o efeito de } \\
\text { dois líquidos } \\
\text { corantes (líquidos } \\
\text { aquosos e ácidos) } \\
\text { e o efeito de cada } \\
\text { posição da } \\
\text { multicamada da } \\
\text { zircônia na } \\
\text { resistência à } \\
\text { flexão. }\end{array}$ & $\begin{array}{l}\text { Zircônia Lava } \\
\text { Esthetic (3M ESPE) }\end{array}$ & $\begin{array}{l}\text { A resistência à flexão } \\
\text { da amostra foi medida } \\
\text { usando uma máquina } \\
\text { de teste universal e a } \\
\text { superfície da amostra } \\
\text { foi observada usando } \\
\text { um microscópio } \\
\text { eletrônico de varredura } \\
\text { de emissão de campo. }\end{array}$ & $\begin{array}{l}\text { A aplicação de } \\
\text { corante líquido não } \\
\text { reduz a força flexural } \\
\text { das multicamadas da } \\
\text { zircônia em todas as } \\
\text { posições. }\end{array}$ \\
\hline $\begin{array}{l}\text { Kou et al } \\
2019^{22}\end{array}$ & $\begin{array}{l}\text { Analisar os efeitos } \\
\text { do } \\
\text { envelhecimento } \\
\text { artificial na } \\
\text { rugosidade de } \\
\text { superfície, } \\
\text { transparência, } \\
\text { transformação de } \\
\text { fase e resistência } \\
\text { à flexão biaxial de } \\
\text { zircônias 5Y-PSZ. }\end{array}$ & $\begin{array}{l}\text { Zircônias: DD cubo } \\
\text { X2 (Dental Direkt } \\
\text { Gmbh) e Prettau } \\
\text { Anterior } \\
\text { (Zirkonzahn). }\end{array}$ & $\begin{array}{l}\text { O envelhecimento } \\
\text { artificial foi realizado } \\
\text { em uma autoclave sob } \\
2 \text { barras de pressão a } \\
134^{\circ} \mathrm{C} \text { por } 10 \text { horas, o } \\
\text { que é estimado em } 30 \\
\text { a } 40 \text { anos in vivo. A } \\
\text { rugosidade superficial } \\
\text { foi mensurada por um } \\
\text { perfilômetro (Precision } \\
\text { Form Talysurf 50, } \\
\text { Taylor Hobson, } \\
\text { Berwyn, USA). A } \\
\text { transmitância por um } \\
\text { espestofotômetro } \\
\text { UV/Vis (Lambda 35, } \\
\text { PerkinElmer, Waltham, } \\
\text { USA). Os testes de } \\
\text { flexão biaxial por uma } \\
\text { máquina de teste (HTE- } \\
\text { 5000N) }\end{array}$ & $\begin{array}{l}\text { O DD cubo X2 e o } \\
\text { Prettau Anterior } \\
\text { parecem ser } \\
\text { relativamente } \\
\text { resistentes ao } \\
\text { envelhecimento. No } \\
\text { entanto, o Prettau } \\
\text { Anterior } \\
\text { provavelmente é um } \\
\text { material menos } \\
\text { estável que o DD } \\
\text { cubo X2, o que } \\
\text { também significa que } \\
\text { a resistência à flexão } \\
\text { do DD cubeX2 } \\
\text { poderia ser mais } \\
\text { previsível. }\end{array}$ \\
\hline
\end{tabular}


Quadro 1. Pesquisas que utilizaram a zircônia ultra translúcida (continuação)

\begin{tabular}{|c|c|c|c|c|}
\hline Autor & Objetivo & Material & Método & Conclusão \\
\hline \multirow[t]{2}{*}{$\begin{array}{l}\text { Daneshpooy } \\
\text { et al } 2019^{23}\end{array}$} & $\begin{array}{l}\text { Avaliar a } \\
\text { correspondência } \\
\text { de cores entre as } \\
\text { pastas try-in e os } \\
\text { respectivos } \\
\text { cimentos } \\
\text { resinosos e } \\
\text { investigar o efeito } \\
\text { da espessura e } \\
\text { das multicamadas } \\
\text { na zircônia ultra } \\
\text { translúcida. }\end{array}$ & $\begin{array}{l}\text { Zircônia KATANA } \\
\text { UTML (Kuraray } \\
\text { Noritake) }\end{array}$ & $\begin{array}{l}\text { A zircônia cúbica foi } \\
\text { preparada e dividida } \\
\text { em cinco grupos de } \\
\text { acordo com a } \\
\text { tonalidade da pasta } \\
\text { try-in e do cimento } \\
\text { resinoso usado, como } \\
\text { segue: Universal, Claro, } \\
\text { Marrom, Branco e } \\
\text { Opaco. A pasta try-in e } \\
\text { o respectivo cimento } \\
\text { resinoso foram } \\
\text { aplicados entre as } \\
\text { amostras e o substrato, }\end{array}$ & $\begin{array}{l}\text { Foi encontrada uma } \\
\text { diferença de cor } \\
\text { perceptível entre as } \\
\text { pastas de teste e o } \\
\text { respectivo cimento } \\
\text { resinoso na maioria } \\
\text { das cores } \\
\text { investigadas. Embora } \\
\text { a concordância das } \\
\text { pastas try-in e o } \\
\text { respetivo cimento } \\
\text { resinoso tenham sido } \\
\text { afetados pela } \\
\text { espessura dos }\end{array}$ \\
\hline & & & $\begin{array}{l}\text { e a avaliação } \\
\text { colorimétrica foi } \\
\text { realizada usando o } \\
\text { sistema CIE-Lab } \\
\text { (SpectroShade Micro). }\end{array}$ & $\begin{array}{l}\text { laminados de } \\
\text { zircônia, as } \\
\text { diferentes regiões da } \\
\text { zircônia ultra } \\
\text { translúcida e } \\
\text { multicamada não } \\
\text { mostraram efeito } \\
\text { significativo. }\end{array}$ \\
\hline $\begin{array}{l}\text { Bacchi et al } \\
2019^{24}\end{array}$ & $\begin{array}{l}\text { Avaliar a } \\
\text { capacidade de } \\
\text { mascaramento do } \\
\text { substrato através } \\
\text { de diferentes } \\
\text { sistemas } \\
\text { cerâmicos } \\
\text { utilizados para } \\
\text { coroas totais e } \\
\text { avaliar a influência } \\
\text { de sua associação } \\
\text { com um cimento } \\
\text { resinoso opaco. }\end{array}$ & $\begin{array}{l}\text { Zircônia + porcelana } \\
\text { (IPS ZirCAD, MO + } \\
\text { IPS e.Max Ceram). } \\
\text { Zircônia + dissilicatp } \\
\text { de lítio (IPS Zir/CAD, } \\
\text { MO + IPS e.Max CAD } \\
\text { LT) e (IPS Zir/CAD, } \\
\text { MO + IPS e.Max CAD } \\
\text { HT) } \\
\text { Dissilicato de lítio + } \\
\text { porcelana (IPS e.Max } \\
\text { Press, HO-0 + IPS } \\
\text { e.Max Ceram). } \\
\text { Zircônia Prettau } \\
\text { anterior } \\
\text { (Zirkonzahn). } \\
\text { Suprinity HT(Vita } \\
\text { Zahnfabrik).Silicato } \\
\text { de lítio Suprinity T } \\
\text { (VITA Zahnfabrik) } \\
\text { Dissilicato de lítio: } \\
\text { IPS e.Max CAD LT } \\
\text { (Ivoclar vivadent) e } \\
\text { IPS e.Max CAD HT } \\
\text { (Ivoclar vivadent). } \\
\text { Cerâmica feldspática } \\
\text { CEREC Block (Vita } \\
\text { Zahnfabrik). } \\
\text { Cerâmica de vidro } \\
\text { reforçada por leúcita } \\
\text { Empress CAD (Ivoclar } \\
\text { vivadent) }\end{array}$ & $\begin{array}{l}\text { As cerâmicas foram } \\
\text { sobrepostas à três } \\
\text { diferentes colorações } \\
\text { de substrato. A } \\
\text { diferença de cor e a } \\
\text { translucidez foram } \\
\text { acessadas por um } \\
\text { espectrofotômetro } \\
\text { (SP60; X-Rite, Grand } \\
\text { Rapids, MI, USA, pela } \\
\text { fórmula do CIEDE2000. }\end{array}$ & $\begin{array}{l}\text { O tipo cerâmico e o } \\
\text { agente de } \\
\text { cimentação à base de } \\
\text { resina opaca } \\
\text { apresentaram efeito } \\
\text { significativo na } \\
\text { capacidade de } \\
\text { mascaramento do } \\
\text { substrato. Todos os } \\
\text { substratos } \\
\text { descoloridos } \\
\text { testados foram } \\
\text { adequadamente } \\
\text { mascarados com } \\
\text { zircônia folheada ou } \\
\text { LDPc. A técnica CAD- } \\
\text { on associada ao } \\
\text { ciento opaco } \\
\text { melhorou a } \\
\text { capacidade de } \\
\text { mascaramento sobre } \\
\text { substratos metálicos. }\end{array}$ \\
\hline
\end{tabular}


Quadro 1. Pesquisas que utilizaram a zircônia ultra translúcida (conclusão)

\begin{tabular}{|c|c|c|c|c|}
\hline Autor & Objetivo & Material & Método & Conclusão \\
\hline $\begin{array}{l}\text { Argen et al } \\
2019^{25}\end{array}$ & $\begin{array}{l}\text { Avaliar a } \\
\text { resistência de } \\
\text { união ao } \\
\text { cisalhamento de } \\
\text { 5Y-PSZ cimentado } \\
\text { em esmalte e } \\
\text { avaliar o padrão } \\
\text { de fratura na } \\
\text { perda de } \\
\text { retenção. }\end{array}$ & $\begin{array}{l}\text { Zircônias: Prettau } \\
\text { Anterior (Zirkonzahn) } \\
\text { e CopraSmile } \\
\text { Symphony 5-layer } \\
\text { (Whitepeaks Dental } \\
\text { Solutions). Dissilicato } \\
\text { de lítio IPS e.Max } \\
\text { Press (Ivoclar } \\
\text { Vivadent). }\end{array}$ & $\begin{array}{l}\text { Todas as cerâmicas } \\
\text { foram cimentadas em } \\
\text { dente humano com } \\
\text { cimento resinoso. A } \\
\text { análise do padrão de } \\
\text { fratura foi obtida } \\
\text { utilizando microscópio } \\
\text { eletrônico de } \\
\text { varredura. }\end{array}$ & $\begin{array}{l}\text { A zircônia } \\
\text { parcialmente } \\
\text { estabilizada mostra } \\
\text { potencial como } \\
\text { material a ser usado } \\
\text { quando a ligação } \\
\text { macromecânica não } \\
\text { é possível, embora } \\
\text { este estudo não } \\
\text { revele como, ou se a } \\
\text { ligação se deteriora } \\
\text { com o tempo. }\end{array}$ \\
\hline $\begin{array}{l}\text { Vafaei et al } \\
2020^{26}\end{array}$ & $\begin{array}{l}\text { Comparar as } \\
\text { propriedades } \\
\text { ópticas de } \\
\text { diferentes } \\
\text { laminados } \\
\text { cerâmicas. }\end{array}$ & $\begin{array}{l}\text { Zircônia KATANA } \\
\text { UTML (Kuraray } \\
\text { Noritake); Zolid FX } \\
\text { (Amann Girrbach) e } \\
\text { dissilicato de lítio IPS } \\
\text { e.Max CAD (Ivoclar } \\
\text { vivadent) }\end{array}$ & $\begin{array}{l}\text { Os laminados } \\
\text { cerâmicos foram } \\
\text { colocados em } \\
\text { substratos usando } \\
\text { pasta try-in nas cores } \\
\text { "bleach“ e "white". As } \\
\text { propriedades ópticas } \\
\text { foram medidas nos } \\
\text { terços incisal, médio e } \\
\text { cervical usando um } \\
\text { espectrofotômetro } \\
\text { EasyShade (VITA). }\end{array}$ & $\begin{array}{l}\text { A cor do substrato, a } \\
\text { cor do cimento e o } \\
\text { material cerâmico } \\
\text { devem ser } \\
\text { cuidadosamente } \\
\text { selecionados para } \\
\text { obter uma estética } \\
\text { ideal em facetas } \\
\text { laminadas. }\end{array}$ \\
\hline $\begin{array}{l}\text { Aljanobi et al } \\
2020^{27}\end{array}$ & $\begin{array}{l}\text { Avaliar a nova } \\
\text { zircônia } \\
\text { translúcida de } \\
\text { multicamadas e a } \\
\text { cerâmica de vidro } \\
\text { para determinar } \\
\text { se sua } \\
\text { translucidez (TP) e } \\
\text { estabilidade de } \\
\text { cor }\left(\Delta E^{\star}\right) \text { são } \\
\text { afetadas pela } \\
\text { termociclagem a } \\
10.000,30.000 \text { e } \\
50.000 \text { ciclos. }\end{array}$ & $\begin{array}{l}\text { Zircônia Prettau } 2 \text { e } \\
\text { Prettau Anterior } \\
\text { (Zirkonzahn). Silicato } \\
\text { de lítio reforçado } \\
\text { com zircônia } \\
\text { Suprinity (VITA). } \\
\text { Dissilicato de lítio IPS } \\
\text { e.max CAD (Ivoclar } \\
\text { Vivadent) }\end{array}$ & $\begin{array}{l}\text { Os valores } L * a * b \text { * } \\
\text { foram registrados } \\
\text { usando um } \\
\text { espectrofotômetro } \\
\text { antes e após a } \\
\text { termociclagem por } \\
10.000,30.000 \text { e } 50000 \\
\text { ciclos. As } \\
\text { translucências das } \\
\text { amostras foram } \\
\text { calculadas usando a } \\
\text { fórmula TP e as } \\
\text { mudanças de cor } \\
\text { foram dadas pelas } \\
\text { diferenças de cor }\left(\Delta E^{\star}\right) \\
\text { em cada intervalo. }\end{array}$ & $\begin{array}{l}\text { Houve um aumento } \\
\text { leve, mas significativo } \\
\text { na translucidez tanto } \\
\text { na zircônia quanto } \\
\text { na vitrocerâmica } \\
\text { após a } \\
\text { termociclagem. Além } \\
\text { disso, todos os } \\
\text { materiais mostraram } \\
\text { uma mudança } \\
\text { significativa de cor } \\
\text { com o tempo; no } \\
\text { entanto, isso não foi } \\
\text { clinicamente } \\
\text { perceptível }\end{array}$ \\
\hline
\end{tabular}




\section{Propriedades ópticas}

A zircônia estabilizada por ítria (3Y-TZP) convencional apresenta pobre translucidez, resultante do alto índice de refração e baixo coeficiente de absorção, comuns em zircônias não cúbicas ${ }^{10}$. Assim, avanços e meios de processamento que incluem modificação na composição química da zircônia, quanto à quantidade de substâncias estabilizadoras e da rede cristalina, foram estudados e implementados com intuito de minimizar os efeitos negativos das propriedades ópticas deste material. À exemplo, diminuiu-se a quantidade de alumina de 0,25\% das zircônias da primeira geração para 0,05\%, proporcionando uma melhora na translucidez da 3Y-TZP $\frac{14}{}$. Entretanto, esse aumento na translucidez ainda não foi o suficiente para que o material pudesse ser empregado em próteses monolíticas para uso na região anterior da boca.

Na tentativa de melhorar as propriedades ópticas da zircônia estabilizada com 3 mol\% de ítria com 0,05\% de alumina, foram adicionadas maiores porções de cristais cúbicos neste material através da dopagem, com variação de 4 a 5 mol\% de óxido de ítrio (4Y-ZP e 5Y-ZP) ${ }^{7}$, para que a mesma apresentasse uma estética mais próxima das cerâmicas vítreas.

Assim, o mercado passou a oferecer dois tipos de materiais de zircônia monolítica: a zircônia opaca e a translúcida. A zircônia opaca com resistência à flexão significativamente maior e indicada para regiões posteriores da boca ${ }^{10}$ e a zircônia translúcida com propriedades estéticas mais naturais que possibilitam seu uso nas regiões posterior ou anterior da boca ${ }^{6}$.

Alguma confusão na nomenclatura tem ocorrido, já que tanto a 3Y-TZP contendo alumina a 0,05\% e a zircônia policristalina estabilizada com 5\% de ítria (5Y-ZP) foram chamadas de "zircônia translúcida". No entanto, esses materiais de zircônia têm propriedades mecânicas e ópticas diferentes ${ }^{14}$. Na tentativa de facilitar o entendimento, a tabela 1 foi elaborada com base na literatura científica atual classificando as gerações da zircônia quanto à translucidez do material.

Tabela 1. Classificação das zircônias

\begin{tabular}{|c|c|c|c|}
\hline $\begin{array}{l}\text { Classificação da zircônia } \\
\text { quanto a translucidez }\end{array}$ & \% de ítria & $\begin{array}{c}\% \text { de } \\
\text { alumina }\end{array}$ & Marcas disponíveis no mercado \\
\hline Zircônia opaca & $\begin{array}{c}3 \text { mol\% de ítria } \\
\text { (3Y-TPZ) }\end{array}$ & $0,25 \%$ & $\begin{array}{c}\text { Ex: Lava Frame (3M ESPE); Vita YZ } \\
\text { T, Prettau Zr (Zahnfabrik) }\end{array}$ \\
\hline Zircônia translúcida & $\begin{array}{r}3 \text { mol\% de ítria } \\
\text { (3Y-TPZ) }\end{array}$ & $0,05 \%$ & $\begin{array}{c}\text { Ex: Lava Plus (3M ESPE); Vita Yz } \\
\text { HT (Zahnfabrik) }\end{array}$ \\
\hline $\begin{array}{l}\text { Zircônia altamente } \\
\text { translúcida }\end{array}$ & $\begin{array}{r}4 \text { mol\% de ítria } \\
\text { (4Y-PSZ) }\end{array}$ & $0,05 \%$ & $\begin{array}{c}\text { Ex: Prettau (Zirkonzahn); BruxZir } \\
\text { (Glidewell); Zenostar (Ivoclar } \\
\text { Vivadent); Katana HT e Katana ML } \\
\text { Noritake (Kuraray Noritake } \\
\text { Dental) }\end{array}$ \\
\hline Zircônia ultra translucida & $\begin{array}{r}5 \text { mol\% de ítria } \\
\text { (5Y-PZ) }\end{array}$ & $0,05 \%$ & $\begin{array}{c}\text { Ex: Lava Esthetic (3M ESPE), } \\
\text { Prettau Anterior (Zirkonzahn), DD } \\
\text { cubo X2 (Dental Direkt), Katana } \\
\text { Zircônia ST e Katana Zircônia UT } \\
\text { Noritake (Kuraray Noritake } \\
\text { Dental) }\end{array}$ \\
\hline
\end{tabular}

Legenda: Classificação dos tipos de zircônia disponíveis atualmente no mercado e porcentagem aproximada da quantidade de ítria e alumina de sua composição. 
A translucidez é uma das propriedades que confere a restauração um efeito natural mais próximo ao da estrutura dentária ${ }^{26}$, sendo uma propriedade óptica muito relevante na escolha de um material cerâmico e sua aplicação clínica quando a estética é requerida5. Um dos grandes problemas das reabilitações orais é conseguir mascarar os diferentes tipos de substratos, tais como dentes clareados e escurecidos, núcleos metálicos fundidos e pilares de implantes. Em um estudo realizado por Harada et al. ${ }^{5}$, a zircônia ultra translúcida com uma espessura de $0,5 \mathrm{~mm}$ se mostrou mais translúcida que as demais zircônias estudadas, porém, mais opaca que o dissilicato de lítio. Estes resultados foram confirmados pelos achados em outros estudos realizados nos anos seguintes $14,18,19$ e corroboraram com a ideia de que este material poderia ser capaz de mascarar substratos escurecidos quando aplicado clinicamente, em coroas totais ou até mesmo quando utilizados em espessuras reduzidas dentro de uma abordagem minimamente invasiva.

Um estudo recente realizado por Bacchi et al. ${ }^{24}$ avaliou in vitro a capacidade de mascaramento do substrato através de diferentes sistemas cerâmicos, multicamada e monolítico, dentre eles a zircônia ultra translúcida (Prettau anterior/ Zirkonzahn), utilizados para coroas totais com espessura de $1,8 \mathrm{~mm}$ e verificou a influência de sua associação com um cimento resinoso opaco, após cimentação em substratos descoloridos. A diferença de cor das cerâmicas monolíticas foi significativamente maior do que as multicamadas. A zircônia ultra translúcida, assim como todas as estruturas monolíticas estudadas, apresentou uma diferença de cor acima do limiar de aceitabilidade clínica. No entanto, o uso do cimento resinoso opaco causou uma redução significativa na diferença de cor das estruturas monolíticas e forneceu valores médios dentro do limite de aceitabilidade $\left(\Delta \mathrm{E}^{*}=1.77\right)$ considerado no estudo $(p<0,001)$. O cimento melhorou a capacidade de mascaramento do substrato para coroas totais monolíticas de maior espessura.

O efeito de espessuras menores da zircônia ultra translúcida, de 0,5 mm e 0,7 mm foi investigado por Daneshpooy et al. $\frac{23}{}$, a proposta do estudo foi avaliar a correspondência de cores entre as pastas try-in e os respectivos cimentos resinosos quando utilizado esta zircônia, assim como o efeito nas suas multicamadas. Para isso, cinco cores de cimento foram avaliadas e a cor foi mensurada em três regiões diferentes da amostra: cervical, média e incisal para cada camada de cerâmica, simultaneamente. Foi possível verificar que os valores da diferença de cor $\left(\Delta \mathrm{E}^{\star}\right)$ entre a pasta de try-in e o cimento resinoso foram afetados pela tonalidade do cimento resinoso $(p<0,05)$ e pela espessura da cerâmica $(p<0,05)$. Quanto maior a espessura da cerâmica, menor variação de cor foi encontrada. As diferentes regiões da zircônia ultra translúcida não mostraram efeito significativo na concordância entre a pasta try-in e o respectivo cimento, no entanto, o valor de $\Delta \mathrm{E}^{\star}$ mais alto esteve relacionado à região incisal, provavelmente pelo fato da região incisal ser menos cromática que as áreas cervical e medial. Um esquema ilustrativo da disposição cromática da cerâmica ultra translúcida é exemplificado na figura 1.

Figura 1. Gradação das multicamadas da zircônia monolítica ultra translúcida

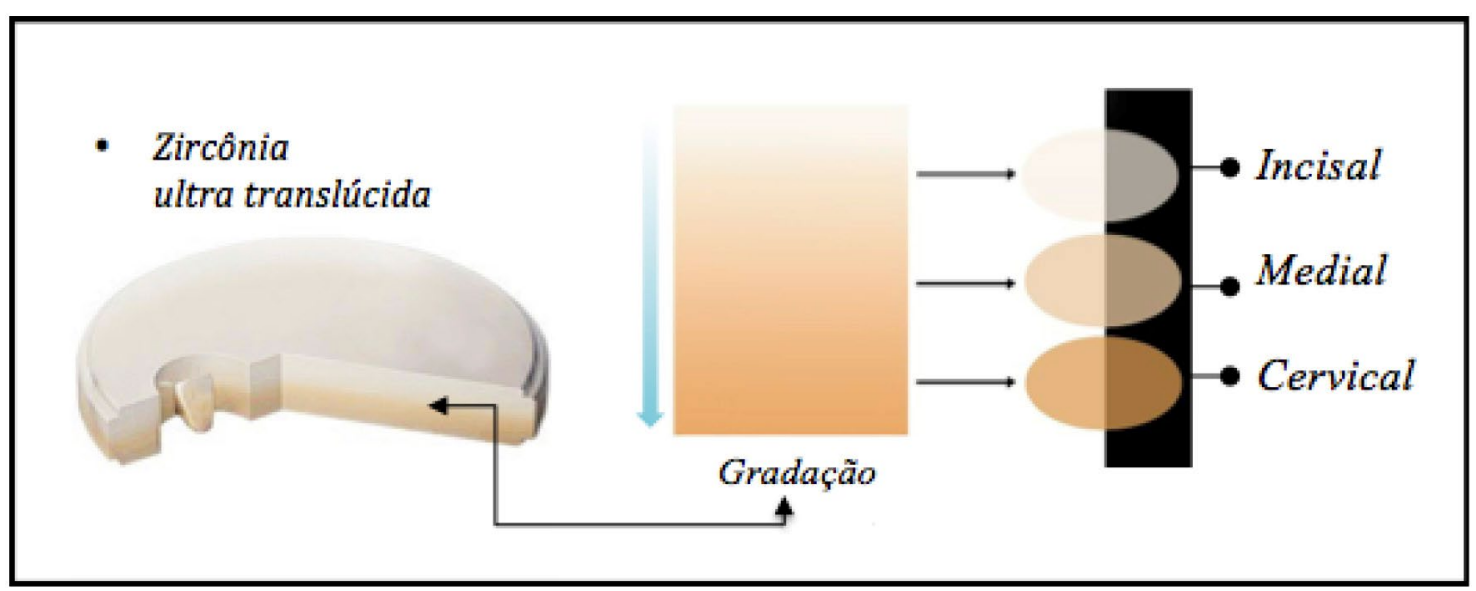

Fonte: Adaptada de Daneshpooy et al. $\underline{23}$. 
A estabilidade de cor da zircônia ultra translúcida é um fator importante que determina a previsibilidade de um tratamento à curto e longo prazo. Para isso, Aljanobi et al.27 avaliaram a estabilidade de cor desta zircônia e do dissilicato de lítio após termociclagem de $10.000,30.000$ e 50.000 ciclos e notaram um aumento leve, porém significativo, no parâmetro de translucidez tanto na zircônia quanto na vitrocerâmica após a termociclagem. Além disso, todos os materiais apresentaram uma mudança significativa de cor com o tempo, no entanto, esses valores não foram clinicamente perceptíveis $\left(\Delta \mathrm{E}^{*} \geq 3.3\right)$.

A translucidez é uma propriedade inerente à zircônia ultra translúcida, comprovada por estudos recentes $5,14,18,19$. No entanto, poucos artigos se propuseram a avaliar a capacidade de mascaramento $24,26 \mathrm{e}$ estabilidade de cor da zircônia ultra translúcida ${ }^{27}$. Os trabalhos utilizam metodologias distintas e adotam valores diferentes de $\Delta \mathrm{E}^{*}$ como sendo clinicamente perceptíveis, o que dificulta a comparação entre os estudos. Dessa forma, mais trabalhos sobre a estabilidade de cor da zircônia ultra translúcida, assim como seu comportamento óptico com o tempo são necessários.

\section{Propriedades mecânicas}

Assim como as características de translucidez, a resistência flexural é uma propriedade importante a ser avaliada na zircônia ultra translúcida para que seja viável o uso deste material nos tratamentos restauradores. Kwon et al. ${ }^{14}$ avaliaram os parâmetros de resistência flexural das 5Y-ZP (Katana UTML), 3Y-TZP (Katana HT) e do dissilicato de lítio (e.Max CAD LT), e observaram diferenças estatisticamente significativas entre a resistência flexural $(P<0,001)$ das diferentes cerâmicas. Os valores de resistência flexural encontrados foram de $1.194 \pm 111 \mathrm{MPa}$ na Katana HT, $688 \pm 159$ MPa na Katana UTML e $460 \pm$ 53 MPa no e.Max CAD LT. Além disso, a resistência de união da zircônia ultra translúcida foi mensurada após jateamento com óxido de alumínio e aplicação de um primer com monômero adesivo MDP (10-metacriloiloxidecil dihidrgênio fosfato), sem haver diferença significante entre as cerâmicas estudadas, mesmo após serem submetidas à envelhecimento em tempos diferentes ( 1 dia ou 150 dias). Pode-se inferir que há uma ligação efetiva entre o cimento resinoso e a 5Y-PSZ após a abrasão de partículas de alumina e a aplicação de monômero adesivo MDP. A implicação clínica do valor de força de união na zircônia ultra translúcida é a possibilidade de usá-la em restaurações não retentivas ${ }^{25}$. Isso a torna um material promissor para aplicabilidade em laminados cerâmicos adotando-se uma abordagem mais conservadora. No entanto, como a 5Y-PSZ foi desenvolvida recentemente, ainda se faz necessário a realização de pesquisas contínuas testando a adesão nesta cerâmica policristalina, uma vez que, ainda não há evidencias que suportem qualquer protocolo de cimentação definitivo para esta cerâmica.

O condicionamento da superfície da zircônia tetragonal com jateamento à ar proporciona retenção mecânica e a resistência à flexão depende do tamanho das partículas abrasivas, pressão do ar e temperatura ${ }^{20}$. Segundo Mao et al. ${ }^{20}$, a infiltração de vidro na superfície da zircônia diminui o módulo de elasticidade da superfície. Essa estrutura elasticamente graduada não melhora apenas a resistência à flexão, como facilita uma ligação durável do cimento resinoso, além de fornecer opções de cor e controlar a translucidez da 5Y-PSZ. Por outro lado, a abrasão a ar e à infiltração por vidro reduzem significativamente a resistência à flexão da 5Y-PSZ, devido ao reduzido teor de transformação $t \rightarrow m$ nas zircônias cúbicas.

As zircônias translúcidas têm uma resistência à flexão menor que a 3Y-TZP quando submetidas ao envelhecimento ${ }^{14}$, as zircônias ultra translúcidas se mostram resistentes, apesar da resistência flexural ser marca dependente ${ }^{22}$. Yu \& Park ${ }^{21}$ avaliaram o efeito de cada posição das multicamadas desta zircônia de acordo com a aplicação dos líquidos corantes e verificaram que a resistência à flexão da zircônia ultra translúcida de multicamada é de 400 a 500 Mpa. Esse valor é superior a $300 \mathrm{MPa}$, portanto, de acordo com a ISO 6872:2015 a resistência à flexão é aceitável para a cerâmica monolítica indicada para restaurações coroas unitárias anteriores e posteriores e próteses de três elementos que não envolvam restauração molar. Além disso, a aplicação de corante líquido, seja aquoso ou ácido, não reduziu a força flexural das multicamadas da zircônia em todas as posições avaliadas. Em suma, as recém-desenvolvidas zircônias tem maior resistência do que a cerâmica de vidro, podendo ser um material adequado para restaurações dentárias ${ }^{18}$. 


\section{Conclusão}

A literatura mostra que a composição química da zircônia ultra translúcida (5Y-PSZ), com maior introdução da fase cúbica, proporciona translucidez maior que as demais zircônias. Apesar da sua resistência flexural ter reduzido, é possível o uso deste material em restaurações unitárias posteriores e anteriores.

\section{Contribuições das autoras}

Almeida CC contribuiu com a coleta dos dados bibliográficos e escrita do presente trabalho. Fernandes MCRC contribuiu com a coleta dos dados bibliográficos e revisão do manuscrito. Lima EMCX contribuiu com a escrita e revisão do manuscrito. Carvalho AO realizou a orientação e supervisão do trabalho, a escrita e revisão do manuscrito.

\section{Conflitos de interesses}

Nenhum conflito financeiro, legal ou político envolvendo terceiros (governo, empresas e fundações privadas, etc.) foi declarado para nenhum aspecto do trabalho submetido (incluindo, mas não se limitando a subvenções e financiamentos, participação em conselho consultivo, desenho de estudo, preparação de manuscrito, análise estatística, etc.).

\section{Referências}

1. Alghazzawi TF, Lemons J, Liu PR, Essig ME, Janowski GM. Evaluation of the optical properties of CAD-CAM generated yttriastabilized zircônia and glass-ceramic laminate veneers. J Prosthet Dent. 2012;107(5):300-8. http://dx.doi.org/10.1016/S00223913(12)60079-1

2. Tabatabaian F, Sharif MJ, Massoumi F, Namdari M. The color masking ability of a zircônia ceramic on the substrates with different values. J Dent Res Dent Clin Dent Prospects. 2017;11(1):7-13. http://dx.doi.org/10.15171/joddd.2017.002

3. Özkurt-Kayahan Z. Monolithic zircônia: A review of the literature. Biomedical Research. 2016;27(4):1427-1436.

4. Kim HK, Kim SH, Lee JB, Han JS, Yeo IS, Ha SR. Effect of the amount of thickness reduction on color and translucency of dental monolithic zircônia ceramics. J Adv Prosthodont. 2016;8(1):37-42. http://dx.doi.org/10.4047/jap.2016.8.1.37

5. Harada K, Raigrodski AJ, Chung KH, Flinn BD, Dogan S, Mancl LA. A comparative evaluation of the translucency of zircônias and lithium disilicate for monolithic restorations. J Prosthet Dent. 2016;116(2):257-63. http://dx.doi.org/10.1016/j. prosdent.2015.11.019
6. Shahmiri R, Standard OC, Hart JN, Sorrell CC. Optical properties of zircônia ceramics for esthetic dental restorations: A systematic review. J Prosthet Dent. 2018;119(1):36-46. http://dx.doi. org/10.1016/j.prosdent.2017.07.009

7. Stawarczyk B, Keul C, Eichberger M, Figge D, Edelhoff D, Lümkemann N. Three generations of zircônia: From veneered to monolithic. Part I. Quintessence Int. 2017;48(5):369-380. http:// dx.doi.org/10.3290/j.qi.a38057

8. Tostes BO, Guimarães RB, Noronha-Filho JD, Botelho GS, Guimarães JGA, Silva EM. Characterization of Conventional and High-Translucency Y-TZP Dental Ceramics Submitted to Air Abrasion. Braz Dent J. 2017;28(1):97-104. http://dx.doi. org/10.1590/0103-6440201701035

9. Ilie N, Stawarczyk B. Quantification of the amount of blue light passing through monolithic zircônia with respect to thickness and polymerization conditions. J Prosthet Dent. 2015;113(2):114-21. http://dx.doi.org/10.1016/j.prosdent.2014.08.013

10. Zhang F, Inokoshi M, Batuk M, Hadermann J, Naert I, Van Meerbeek $B$ et al. Strength, toughness and aging stability of highly-translucent Y-TZP ceramics for dental restorations. Dent Mater. 2016;32(12):327-337. http://dx.doi.org/10.1016/j. dental.2016.09.025

11. Matsuzaki F, Sekine H, Honma S, Takanashi T, Furuya K, Yajima $Y$ et al. Translucency and flexural strength of monolithic translucent zircônia and porcelain-layered zircônia. Dent Mater J. 2015;34(6):910-7. http://dx.doi.org/10.4012/dmj.2015-107

12. Lohbauer U, Reich S. Antagonist wear of monolithic zircônia crowns after 2 years. Clin Oral Investig. 2017;21(4):1165-1172. http://dx.doi.org/10.1007/s00784-016-1872-6

13. Tuncel I, Turp I, Üşümez A. Evaluation of translucency of monolithic zircônia and framework zircônia materials. J Adv Prosthodont. 2016;8(3):181-6. http://dx.doi.org/10.4047/ jap.2016.8.3.181

14. Kwon SJ, Lawson NC, McLaren EE, Nejat AH, Burgess JO. Comparison of the mechanical properties of translucent zircônia and lithium disilicate. J Prosthet Dent. 2017;120(1):132-137. http:// dx.doi.org/10.1016/j.prosdent.2017.08.004

15. Putra A, Chung KH, Flinn BD, Kuykendall T, Zheng C, Harada $\mathrm{K}$ et al. Effect of hydrothermal treatment on light transmission of translucent zircônias. J Prosthet Dent. 2017;118(3):422-429. http:// dx.doi.org/10.1016/j.prosdent.2016.10.024

16. Ghodsi S, Jafarian Z. A Review on Translucent Zircônia. Eur J Prosthodont Restor Dent. 2018;26(2):62-74. http://dx.doi. org/10.1922/EJPRD_01759Ghodsi13

17. Inokoshi M, Shimizu H, Nozaki K, Takagaki T, Yoshihara K, Nagaoka $\mathrm{N}$ et al. Crystallographic and morphological analysis of sandblasted highly translucent dental zircônia. Dent Mater. 2018;34(3):508-518. http://dx.doi.org/10.1016/j.dental.2017.12.008 
18. Zhao M, Sun Y, Zhang J, Zhang Y. Novel Translucent and Strong Submicron Alumina Ceramics for Dental Restorations. J Dent Res. 2018; 97(3):289-295. http://dx.doi.org/10.1177/0022034517733742

19. Yan J, Kaizer MR, Zhang Y. Load-Bearing Capacity of Lithium Disilicate and Ultra-Translucent Zircônias. J Mech Behav Biomed Mater. 2018;88:170-175. http://dx.doi.org/10.1016/j. jmbbm.2018.08.023

20. Mao L, Kaizer MR, Zhao M, Guo B, Song YF, Zhang Y. Graded Ultra-Translucent Zircônia (5Y-PSZ) for Strength and Functionalities. J Dent Res. 2018;97(11):1222-1228. http://dx.doi. org/10.1177/0022034518771287

21. Yu NK, Park MG. Effect of different coloring liquids on the flexural strength of multilayered zircônia. J Adv Prosthodont. 2019;11(4):209-214. http://dx.doi.org/10.4047/jap.2019.11.4.209

22. Kou W, Garcrielsson K, Borhani A, Calborg M, Thorén MM. The effects of artificial aging on high translucent zircônia. Biomater Investig Dent. 2019;6(1): 54-60. http://dx.doi.org/10.1080/2641527 $\underline{5.2019 .1684201}$

23. Daneshpooy M, Azar FP, Oskoee PA, Bahari M, Asdagh $\mathrm{S}$, Khosravani SR. Color agreement between try-in paste and resin cement: Effect of thickness and regions of ultratranslucent multilayered zircônia veneers. J Dent Res Dent Clin Dent Prospects. 2019;13(1):61-67. http://dx.doi.org/10.15171/ joddd.2019.010
24. Bacchi A, Boccardi S, Alessandretti R, Pereira GKR. Substrate masking ability of bilayer and monolithic ceramics used for complete crowns and the effect of association with an opaque resin-based luting agent. J Prosthodont Res. 2019;63(3):321-326. http://dx.doi.org/10.1016/j.jpor.2019.01.005

25. Ågren M, Kou W, Thorén MM. Bond strength of surface-treated novel high translucent zircônia to enamel. Biomater Investig Dent. 2019;6(1):35-42. http://dx.doi.org/10.1080/26415275.2019.16842 $\underline{00}$

26. Vafaei F, Izadi A, Abbasi S, Farhadian M, Bagheri Z. Comparison of Optical Properties of Laminate Veneers Made of Zolid FX and Katana UTML Zircônia and Lithium Disilicate Ceramics. Front Dent. 2019;16(5):357-368. http://dx.doi.org/10.18502/fid.v16i5.2284

27. Aljanobi G, Al-Sowygh ZH. The Effect of Thermocycling on the Translucency and Color Stability of Modified Glass Ceramic and Multilayer Zircônia Materials. Cureus. 2020;12(2):e6968. http:// dx.doi.org/10.7759/cureus.6968 